\title{
Enhanced surface passivation of predictable quantum efficient detectors by silicon nitride and silicon oxynitride/silicon nitride stack
}

Therese Sørheim Stokkan, Halvard Haug, Chi Kwong Tang, Erik Stensrud Marstein, and Jarle Gran

Citation: Journal of Applied Physics 124, 214502 (2018); doi: 10.1063/1.5054696

View online: https://doi.org/10.1063/1.5054696

View Table of Contents: http://aip.scitation.org/toc/jap/124/21

Published by the American Institute of Physics

\section{Articles you may be interested in}

Ultra-fast adaptive optical micro-lens arrays based on stressed liquid crystals

Journal of Applied Physics 124, 214501 (2018); 10.1063/1.5057393

Solution of the time dependent Schrödinger equation leading to Fowler-Nordheim field emission

Journal of Applied Physics 124, 213104 (2018); 10.1063/1.5066240

Challenges in materials and devices for resistive-switching-based neuromorphic computing Journal of Applied Physics 124, 211101 (2018); 10.1063/1.5047800

The origin of carbon-related carrier compensation in p-type GaN layers grown by MOVPE Journal of Applied Physics 124, 215701 (2018); 10.1063/1.5057373

Growth of SiGe epitaxial quantum dots on patterned Si (001) surfaces by in situ annealing of initially conformal layers

Journal of Applied Physics 124, 204302 (2018); 10.1063/1.5050921

Unveiling the dual role of chemically synthesized copper doped zinc oxide for resistive switching applications Journal of Applied Physics 124, 214901 (2018); 10.1063/1.5052619

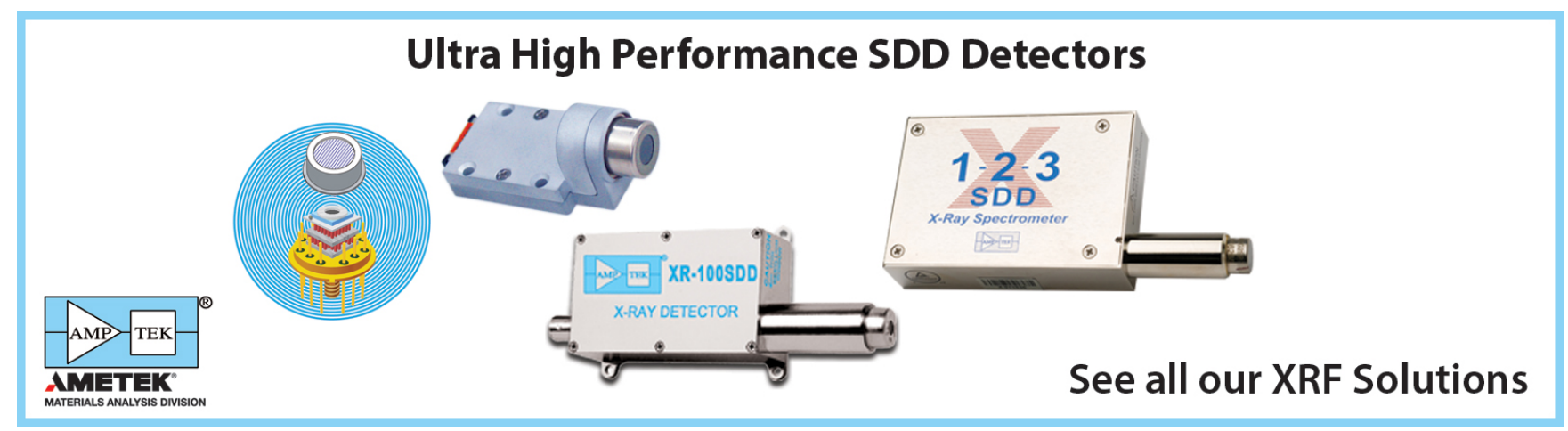




\title{
Enhanced surface passivation of predictable quantum efficient detectors by silicon nitride and silicon oxynitride/silicon nitride stack
}

\author{
Therese Sørheim Stokkan, ${ }^{1,2}$ Halvard Haug, ${ }^{3, a)}$ Chi Kwong Tang, ${ }^{1}$ \\ Erik Stensrud Marstein, ${ }^{3}$ and Jarle Gran ${ }^{1}$ \\ ${ }^{1}$ Justervesenet (JV), P.O. Box 170, 2027 Kjeller, Norway \\ ${ }^{2}$ Department of Physics/Center for Materials Science and Nanotechnology, University of Oslo, P.O. Box 1048 \\ Blindern, N-0316 Oslo, Norway \\ ${ }^{3}$ Department for Solar Energy, Institute for Energy Technology, P.O. Box 40, 2027 Kjeller, Norway
}

(Received 2 September 2018; accepted 12 November 2018; published online 3 December 2018)

\begin{abstract}
In this paper, we investigate three different passivating films for use in predictable quantum efficient detectors: two monolayer films of $\mathrm{SiN}_{\mathrm{x}}$ with different compositions and one double-layer stack of $\mathrm{SiN}_{\mathrm{x}} \mathrm{O}_{\mathrm{y}}$ capped with $\mathrm{SiN}_{\mathrm{x}}$, all deposited on very high resistivity silicon substrates. In addition to the conventional characterization methods, we also utilize the novel method of photoluminescence imaging under applied bias (PL-V) and high voltage soaking to modulate the fixed charge density $\mathrm{Q}_{\mathrm{f}}$ in the layers. All films exhibit very good passivating properties after deposition and annealing, with the oxynitride stack providing the best passivation, resulting in an effective carrier lifetime close to $20 \mathrm{~ms}$. This value is explained by a relatively high fixed charge density of $\mathrm{Q}_{\mathrm{f}}=1.12 \times 10^{12} \mathrm{~cm}^{-2}$ and low interface defect density $\left(\mathrm{S}_{0, \mathrm{n}}=6.0 \times 10^{2} \mathrm{~cm} / \mathrm{s}\right)$, giving a chemical passivation which is an order of magnitude better than the investigated nitrides. Both nitride films were readily charged by voltage soaking, increasing the effective carrier lifetime by about $20 \%$. Based on the passivating properties, photodetector device simulations predict that self-induced photodiodes made with any of these passivation layers will have an internal quantum deficiency well below $1 \mathrm{ppm}$ for selected wavelengths at room temperature, and all the investigated materials are thus good candidates for use as passivating layers in such photodiodes. Published by AIP Publishing. https://doi.org/10.1063/1.5054696
\end{abstract}

\section{INTRODUCTION}

In the search for a new primary standard for measuring optical power, the predictable quantum efficient detector (PQED) has proven to be a good candidate as it has been demonstrated to have a very low internal quantum deficiency (IQD) with an uncertainty below $100 \mathrm{ppm}^{1,2}$ This type of diode is based on an induced junction, where the fixed charge in a dielectric surface layer induces a $p$-n junction in the underlying silicon substrate. The layer also provides surface passivation by minimizing surface recombination. Generally, there are two different strategies for improved surface passivation: (i) chemical passivation, where the number of recombination-active interface states at the surface is reduced, and (ii) field-effect passivation, where the concentration of one type of charge carrier at the interface is drastically reduced due to the electrical field. The former is achieved through passivating electrically active defects at the silicon surface, such as silicon dangling bonds. The latter is achieved by the fixed charges in the dielectric repelling either electrons or holes, depending on the type of charge.

Several materials may be suitable as passivating layers for silicon devices. $\mathrm{SiO}_{2}$, a standard coating in the solar cell industry, and $\mathrm{Al}_{2} \mathrm{O}_{3}$ have both been demonstrated to work as surface passivation layers of self-induced photodiodes. ${ }^{1-3}$ Amorphous hydrogenated silicon nitride films, a-SiN $: H$

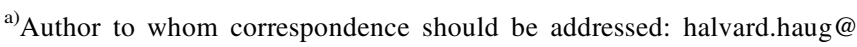
ife.no
}

(here abbreviated as $\mathrm{SiN}_{\mathrm{x}}$ ), also have a long history in the solar cell industry, as they outperform standard coatings in reducing optical losses and in providing both surface and bulk passivation ${ }^{4}$ but has not yet been realized as an induced photodiode. A recent study ${ }^{5}$ has demonstrated the possibility to increase the fixed charge in $\mathrm{SiN}_{\mathrm{x}}$ layers deposited on highresistivity silicon substrates suitable for photodetector applications. The increased fixed charge leads to reduced effective surface recombination velocities, making $\mathrm{SiN}_{\mathrm{x}}$ a promising candidate as passivation layer for photodiodes. Another strong candidate is a double-layer structure of amorphous hydrogenated silicon-rich oxynitride (here abbreviated as $\mathrm{SiN}_{\mathrm{x}} \mathrm{O}_{\mathrm{y}}$ ) capped with $\mathrm{SiN}_{\mathrm{x}}$, as this has proven an excellent surface passivation layer for silicon solar cell applications. Such $\operatorname{SiN}_{\mathrm{x}} \mathrm{O}_{\mathrm{y}} / \mathrm{SiN}_{\mathrm{x}}$ stack structures have been investigated both in our previous work and by other groups and are attractive for use in PQEDs as they also have a large positive fixed charge density, and at the same time can be processed with a lower interface defect density at the $\mathrm{SiN}_{\mathrm{x}} \mathrm{O}_{\mathrm{y}} / \mathrm{c}-\mathrm{Si}$ interface. ${ }^{6-9}$

The simple structure of an induced junction diode is desirable for photodiode applications as it makes fabrication relatively simple while making it suitable to model and predict their response with high accuracy. Models predict that lowering the surface recombination velocity (SRV) will lower the IQD of the photodiode. In addition, it shows that increasing the fixed charge density, $\mathrm{Q}_{\mathrm{f}}$, of the surface reduces the internal losses. $\mathrm{Q}_{\mathrm{f}}$ and SRV have been identified to be the key parameters defining the IQD of induced photodiodes and are therefore the parameters of interest in this study of passivation materials. In combination with experimental 
measurements of $\mathrm{Q}_{\mathrm{f}}$ and $\mathrm{SRV}$, detailed device modeling can be used for accurate prediction of the quantum efficiency of PQEDs. The key parameters are traditionally assessed using capacitance-voltage (C-V) and minority carrier lifetime measurements.

In this paper, we use the $\mathrm{C}-\mathrm{V}$ and minority carrier lifetime (hereafter: lifetime) characterization methods to investigate three different passivating films as potential candidates for use in PQEDs: two monolayer films of $\mathrm{SiN}_{\mathrm{x}}$ with different compositions and one double-layer stack of $\mathrm{SiN}_{\mathrm{x}} \mathrm{O}_{\mathrm{y}}$ capped with $\mathrm{SiN}_{\mathrm{x}}$ (oxynitride stack for short), all deposited on a very high resistivity silicon substrate. In addition to the conventional characterization methods, we also utilize the novel method of photoluminescence imaging under applied bias (PL-V) and high voltage soaking to modulate $\mathrm{Q}_{\mathrm{f}}$ in the layers. ${ }^{10,11}$ In combination with detailed simulation models, this approach provides a fundamental understanding of the studied surface layers and the possibility to predict the response of a final device. Finally, we have used accurate 3D models to predict the IQD if photodiodes were manufactured with the different passivation layers examined in this study.

\section{EXPERIMENTAL}

The substrates were $4 \mathrm{in}$. high-quality polished p-type [100] monocrystalline Float Zone wafers with a nominal thickness of $525 \mu \mathrm{m}$ and a resistivity of $>10000 \Omega \mathrm{cm}$. Prior to layer deposition, the wafers were divided into two and received a $30 \mathrm{~s}$ dip in 5\% HF solution followed by deionized water rinsing. All passivation layers were deposited using high-frequency plasma-enhanced chemical vapor deposition (PECVD) with an Oxford instruments PlasmaLab 133 direct plasma system at $400^{\circ} \mathrm{C}$.

For the $\mathrm{SiN}_{\mathrm{x}}$ layers, silane, ammonia $\left(\mathrm{NH}_{3}\right)$, and nitrogen $\left(\mathrm{N}_{2}\right)$ were used. The gas-flux ratios for the nitride layers, $R_{\mathrm{G}}=\left[\mathrm{SiH}_{4}\right] /\left[\mathrm{NH}_{3}\right]$, were chosen based on initial experimentation and literature. ${ }^{4,5}$ The double-layer stack consisted of a $\sim 13 \mathrm{~nm}$ thick layer of $\operatorname{SiN}_{\mathrm{x}} \mathrm{O}_{\mathrm{y}}$ capped with $\mathrm{SiN}_{\mathrm{x}}$. For the $\mathrm{SiN}_{\mathrm{x}} \mathrm{O}_{\mathrm{y}}$ layer, silane $\left(\mathrm{SiH}_{4}\right)$, hydrogen $\left(\mathrm{H}_{2}\right)$, and nitrous oxide $\left(\mathrm{N}_{2} \mathrm{O}\right)$ were used as process gases. Film thickness and refractive index were measured by ellipsometry. These measurements also gave an estimate of the absorption coefficients of the films, $\mathrm{k}$. However, the measurement setup used was not ideal for measuring these values, so the values are therefore associated with high uncertainty. Further studies of the absorption in the films are therefore necessary. Parameters measured by ellipsometry are listed in Table I, and sketches of the symmetrically passivated samples are shown in Fig. 1.

TABLE I. PECVD gas-flux ratios for nitride layers, $\mathrm{R}_{\mathrm{G}}=\left[\mathrm{SiH}_{4}\right] /\left[\mathrm{NH}_{3}\right]$. Layer thickness, $\mathrm{d}$, refractive index, $\mathrm{n}$, and absorption coefficient, $\mathrm{k}$, measured by ellipsometry. The values for $\mathrm{n}$ and $\mathrm{k}$ are given for a wavelength of $630 \mathrm{~nm}$.

\begin{tabular}{lcccc}
\hline \hline Sample & $\mathrm{R}_{\mathrm{G}}$ & $\mathrm{d}(\mathrm{nm})$ & $\mathrm{n}$ & $\mathrm{k}$ \\
\hline $\mathrm{SiN}_{\mathrm{x}}(\mathrm{A})$ & 0.25 & 95 & 1.85 & $3.2 \times 10^{-7}$ \\
$\mathrm{SiN}_{\mathrm{x}}(\mathrm{B})$ & 0.50 & 99 & 1.89 & $4.0 \times 10^{-7}$ \\
$\mathrm{SiN}_{\mathrm{x}} \mathrm{O}_{\mathrm{y}} / \mathrm{SiN}_{\mathrm{x}}$ & $\ldots / 1.00$ & $13 / 102$ & 2.05 & $4.3 \times 10^{-4}$ \\
\hline \hline
\end{tabular}

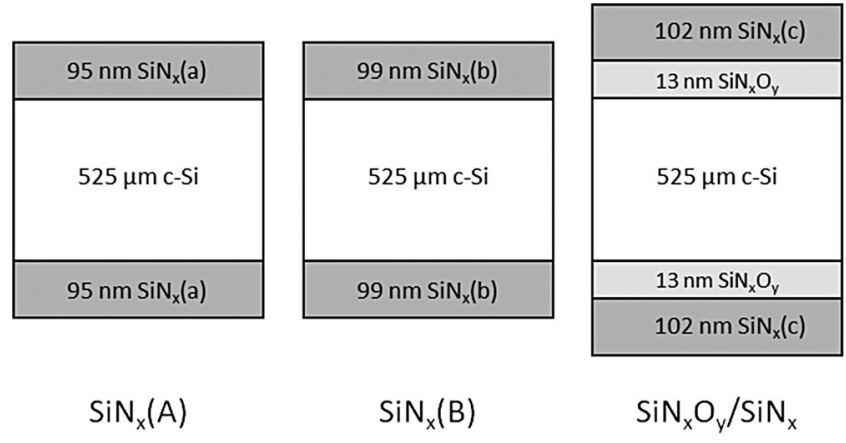

FIG. 1. Sketches of symmetrically passivated samples. Letters a, b, and c in parentheses indicate $\mathrm{SiN}_{\mathrm{x}}$ layers of different compositions.

The chosen process condition for the passivation layers was determined based on a number of test samples and optimized for the following criteria: (1) low SRV, (2) good dielectric quality, ensuring relatively well-behaved properties during electrical characterization, and (3) low optical absorption in the visible part of the spectrum. In a previous work on similar layers ${ }^{11}$ we found that a higher ratio of $R_{G}$ results in a more Si-rich film and a higher $\mathrm{H}$ content, which generally improves the passivation properties (in the end approaching that of a-Si:H) but decreases the dielectric properties. The chosen values for $R_{G}$ thus represent a compromise of the two. For the $\mathrm{SiN}_{\mathrm{x}} \mathrm{O}_{\mathrm{y}} / \mathrm{SiN}_{\mathrm{x}}$ stacks, a higher $R_{G}$ value could be used for the capping $\operatorname{SiN}_{\mathrm{x}}$ layer due to the excellent dielectric properties of the $\operatorname{SiN}_{\mathrm{x}} \mathrm{O}_{\mathrm{y}}$ itself. For each of the three passivating layers, two types of samples were made: symmetrical double-sided depositions for Photoluminescence (PL) and Quasi-Steady State Photo Conductance (QSSPC) measurements (lifetime samples) and single-sided depositions for $\mathrm{C}-\mathrm{V}$ measurements. For the single-sided samples, rear contacts were made by depositing $\mathrm{Al}$ onto the rear (Si side) of the wafers, followed by annealing at $400{ }^{\circ} \mathrm{C}$ for $\sim 9 \mathrm{~min}$. The annealing was performed for two reasons: During the annealing, hydrogen from the PECVD layers diffuses to the interface and passivates recombination active dangling bonds, thus lowering the surface recombination rate. Second, the rear side $\mathrm{Al}$ on the rear of the single side passivated samples forms a high-quality ohmic contact to the Si wafers. The annealing temperature and time was chosen based on a previous optimization of these two effects. Circular Al electrodes of diameters 1.5, 2.0, and $2.5 \mathrm{~mm}$ were then deposited on top of the passivating layer, creating metal-insulator-semiconductor (MIS) structures. The doublesided samples received the same heat treatment, and $9.0 \mathrm{~mm}$ diameter circular $\mathrm{Al}$ electrodes were deposited on top of the passivating layer. The large sizes of the electrodes were chosen to minimize the effect of lateral diffusion of charge carriers at the edges during PL-V measurements. ${ }^{12}$ In addition to the top electrodes, silver paste contacts were applied to the $\mathrm{Si}$ substrate on the rear side by scraping through the surface layer with a diamond pen.

QSSPC lifetime measurements ${ }^{13}$ (using a WCT-120 setup from Sinton Instruments in transient mode) were performed before and after annealing, and prior to electrode deposition on all lifetime samples. Dark $\mathrm{C}-\mathrm{V}$ measurements 
were performed using a four probe Keithley 4200-SCS semiconductor characterization system with a frequency of 2-10 $\mathrm{kHz}$. From these measurements, we can calculate the fixed charge in the dielectric films using the relation

$$
Q_{f}=\frac{C_{i}}{A q}\left(\Delta \varphi_{m s}-V_{f b}\right)
$$

where $V_{f b}$ is the flat band voltage obtained from the $\mathrm{C}-\mathrm{V}$ curves, $C_{i}$ is the insulator capacitance, $A$ is the electrode area, and $\Delta \varphi_{m s}$ is the metal-semiconductor work function difference. ${ }^{14}$ A common problem for such measurements is the shifting of the absolute value for the insulator capacitance, $\mathrm{C}_{\mathrm{i}}$, due to frequency dependent series resistance in the MIS structure, ${ }^{12,13}$ and this effect becomes pronounced in our case due to the high resistivity of the substrate. We therefore use the theoretical value $C_{\mathrm{i}}=\varepsilon_{0} \varepsilon_{\mathrm{i}} A / d_{\mathrm{i}}$ in calculations of the fixed charge.

Soaking experiments were conducted by applying an increasingly negative soaking voltage across the MIS structures for $100 \mathrm{~s}$ prior to each C-V measurement. Starting at $-10 \mathrm{~V}$, the samples were soaked at increasing negative voltage until the MIS structure broke down and $Q_{f}$ was measured between each charging step.

Spatially resolved steady state lifetime measurements were obtained by combining QSSPC measurements with PL imaging ${ }^{15}$ (using a LIS-R1 PL imaging setup from BT imaging with an excitation wavelength of $808 \mathrm{~nm}$ ). Photoluminescence imaging under applied bias (PL-V) measurements were conducted as described in the work by Haug et $a l .{ }^{10}$ With this technique, PL images were recorded while the samples were subject to an external bias over the rear side dielectric passivation layer, ranging from $10 \mathrm{~V}$ to $-10 \mathrm{~V}$ in steps of $0.2 \mathrm{~V}$. This has the effect of changing the band bending in the Si close to the affected surface, in a similar way to when fixed charges are present in the dielectric layer. In addition, a soaking experiment equivalent to the one described above was also conducted in the PL setup, where the samples were soaked by an external voltage source prior to each PL measurement. For the larger metal pads used for the lifetime samples, MIS structure breakdown happened between $-35 \mathrm{~V}$ and $-60 \mathrm{~V}$.

The 2D simulations were performed using Cogenda Genius TCAD. ${ }^{16}$ Experimental input about sample geometry, doping, etc. was used to build a model of the lifetime samples, and the results of the QSSPC and PL-V lifetime measurement were simulated by calculating the excess carrier density and optical generation rate in the middle of the sample. The implemented bulk recombination processes include band-to-band, Shockley-Read-Hall (SRH), and Auger. The surface recombination rate $U_{\text {surf }}$ is described by an extended SRH theory, assuming a single level midgap defect $^{17}$ and can be written as

$$
S_{\text {eff }}=\frac{1}{\Delta n_{\text {bulk }}} \times \frac{p_{s} n_{s}-n_{i}^{2}}{\left(n_{s}+n_{i}\right) / S_{0, p}+\left(p_{s}+n_{i}\right) / S_{0, n}},
$$

where $\Delta n_{b u l k}$ is the excess carrier density on the neutral bulk of the sample, $p_{s}\left(n_{s}\right)$ is the hole (electron) concentration at the surface, $n_{i}$ is the intrinsic carrier concentration, and
$S_{0, p}\left(S_{0, n}\right)$ is the SRV parameter for holes (electrons). The SRV parameters for electrons and holes are defined as

$$
\begin{aligned}
& S_{0, n}=\sigma_{n} v_{t h} N_{i t}, \\
& S_{0, p}=\sigma_{p} v_{t h} N_{i t},
\end{aligned}
$$

where $\sigma_{n}$ and $\sigma_{p}$ are the capture cross sections for electrons and holes, $v_{t h}$ is the thermal velocity of charge carrier, and $N_{i t}$ is the (midgap) defect density per area at the interface. Using the available experimental tools, it is not possible to quantify $N_{i t}$ and $\sigma_{n / p}$ independently. However, as it is always the product of the two which determines the impact of the surface defects on the surface recombination rate, the so-called chemical passivation, and it is therefore $S_{0 n}$ and $S_{0 p}$ which are the important quantities for describing device performance. In addition to the chemical passivation, the surface recombination is also limited by field-effect passivation, determined by the band bending conditions at the surface caused by the fixed charges $Q_{f}$, and which again determines $n_{s}$ and $p_{s}$ in Eq. (2). The surface recombination properties can therefore be uniquely described by $S_{0 n}, S_{0 p}$, and $Q_{f}$, and these three parameters were also used as fitting parameters when fitting the simulated data to the experimental lifetime curves. Finally, the internal quantum deficiency of full PQED detectors was simulated, using the same recombination parameters and fixed charge densities for the three different charged passivation layers.

\section{RESULTS AND DISCUSSION}

Figure 2 shows the experimental and simulated QSSPC curves after annealing of the samples. We see that $\operatorname{SiN}_{\mathrm{x}}(\mathrm{A})$ and $\operatorname{SiN}_{\mathrm{x}}(\mathrm{B})$ have similar effective lifetimes, whereas the values for $\mathrm{SiN}_{\mathrm{x}} \mathrm{O}_{\mathrm{y}} / \mathrm{SiN}_{\mathrm{x}}$ is about four times as high at the lower injection levels. The lifetime curves were also measured before annealing (not shown). A 50\%-70\% improvement of the carrier lifetime was observed after annealing for all samples, caused by a lowering of the surface defect concentration due to $\mathrm{H}$ diffusion, as described above. Similar

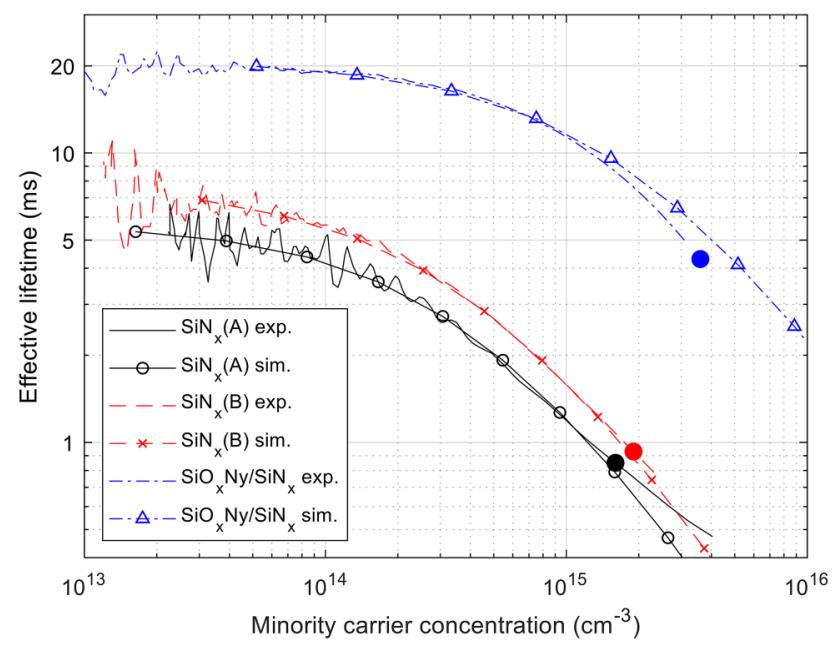

FIG. 2. Effective lifetime as a function of minority carrier concentration obtained by QSSPC measurements after annealing. The simulated data give a remarkably good agreement with the measured curves for each sample. The filled circles mark the calibration point used for each sample. 
TABLE II. Simulation fitting parameters for 2D simulation with Cogenda Genius TCAD.

\begin{tabular}{lcccc}
\hline \hline Sample & $\begin{array}{c}S_{\text {On }} \\
(\mathrm{cm} / \mathrm{s})\end{array}$ & $\begin{array}{c}S_{O p} \\
(\mathrm{~cm} / \mathrm{s})\end{array}$ & $\begin{array}{c}Q_{f, O} \\
\left(\mathrm{~cm}^{-2}\right)\end{array}$ & $\begin{array}{c}S_{\text {eff }} \text { at } \Delta n=10^{14} \mathrm{~cm}^{-3} \\
(\mathrm{~cm} / \mathrm{s})\end{array}$ \\
\hline $\mathrm{SiN}_{\mathrm{x}}(\mathrm{A})$ & $1.7 \times 10^{4}$ & $3.2 \times 10^{3}$ & $2.7 \times 10^{11}$ & 5.9 \\
$\mathrm{SiN}_{\mathrm{x}}(\mathrm{B})$ & $6.0 \times 10^{3}$ & $5.5 \times 10^{3}$ & $3.5 \times 10^{11}$ & 4.5 \\
$\mathrm{SiN}_{\mathrm{x}} \mathrm{O}_{\mathrm{y}} / \mathrm{SiN}_{\mathrm{x}}$ & $6.0 \times 10^{2}$ & $1.4 \times 10^{3}$ & $1.15 \times 10^{12}$ & 1.3 \\
\hline \hline
\end{tabular}

improvements over the conventional SiNx layers have recently also been found by other groups. ${ }^{6,9}$ The lifetimes of all the samples are highly injection dependent, and the simulations show a very good fit with the experimental data. The best fit parameters for the simulation model, which were also used for the PL-V simulations in Fig. 4, are given in Table II. Only at higher injection levels, the simulations deviate slightly. At these injection levels, Auger recombination begins to contribute to the effective lifetime. Thus, the parametrization of Auger in the simulations can affect the shape of the curve. ${ }^{18}$ Furthermore, it must be noted that the simulation structure has not implemented a damaged layer at the interfaces ${ }^{19}$ and that the surface recombination model is based on SRH for a mid-gap single level defect. The simplification of the simulation model can also affect the shape of the curves.

Figure 3 shows the measured $Q_{f}$ values as well as the effect of subsequent soaking voltage on all the samples. Note that the $Q_{f}$ values before charging correspond well with the best-fit $Q_{f}$ values used to simulate the lifetime data (Table II). Generally, the $Q_{f}$ in the current samples prior to charging is lower than most values published in the literature on $\mathrm{SiN}_{\mathrm{x}}$ for solar cell applications, indicating that charge increasing techniques might be necessary. For the

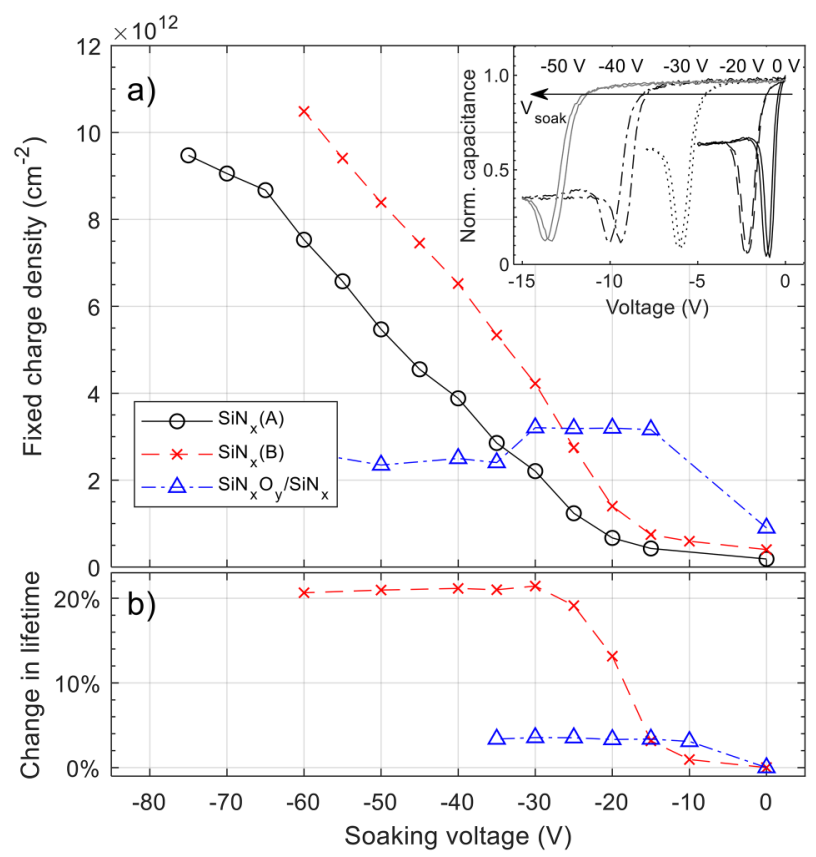

FIG. 3. (a) Fixed charge density as a function of soaking voltage (C-V measurements). Inset: $\mathrm{C}-\mathrm{V}$ curves from sample $\mathrm{SiN}_{\mathrm{x}}(\mathrm{A})$, displaying the shift in flat band voltage caused by increasingly negative soaking bias. (b) Change in lifetime as a function of soaking voltage (PL measurements).
$\mathrm{SiN}_{\mathrm{x}} \mathrm{O}_{\mathrm{y}} / \mathrm{SiN}_{\mathrm{x}}$ stack, we find a $Q_{f}$ in the same range as what was found in Ref. $8\left(1.09-1.72 \times 10^{12}\right)$. In Ref. 6 , the minimum $Q_{f}$ was assumed to be much higher $\left(>10^{13} \mathrm{~cm}^{-2}\right)$, but the value was only based on the lack of a flat band signature in the CV curve and is thus not taken as a relevant comparison here.

The inset in Fig. 3(a) shows the shift in the C-V curves for $\mathrm{SiN}_{\mathrm{x}}(\mathrm{A})$ with increasing soaking voltage, resulting in a clear shift of the curve toward more negative voltage, indicating increased fixed charge density. Both $\operatorname{SiN}_{\mathrm{x}}(\mathrm{A})$ and $\operatorname{SiN}_{\mathrm{x}}(\mathrm{B})$ were readily charged, achieving fixed charge densities close to or above $1 \times 10^{13} \mathrm{~cm}^{-2}$. The $\operatorname{SiN}_{\mathrm{x}} \mathrm{O}_{\mathrm{y}} / \mathrm{SiN}_{\mathrm{x}}$ layer, on the other hand, only retained charge after the initial soaking at $-15 \mathrm{~V}$. Thereafter, the fixed charge density leveled out before stabilizing to a slightly decreased level from $-35 \mathrm{~V}$. Seiffe et al. ${ }^{6}$ observed a $Q_{f}$ value for the reference $\mathrm{SiN}_{\mathrm{x}}$ layer of $4.1 \times 10^{12} \mathrm{~cm}^{2}$ after voltage soaking at $-10 \mathrm{~V}$; in comparison, a soaking voltage of $-30 \mathrm{~V}$ and $-40 \mathrm{~V}$ was needed to obtain the same $Q_{f}$ in the $\mathrm{SiN}_{\mathrm{x}}$ layers studied here, which may partly be caused by a higher film thickness.

For $\mathrm{SiN}_{\mathrm{x}}(\mathrm{B})$ in Fig. 3(b), there is a sharp initial increase in the effective lifetime from $-10 \mathrm{~V}$ before a stabilization at $-30 \mathrm{~V}$. The maximum change in the effective lifetime is approximately $20 \%$.

It should be noted that the lifetime curves stabilize before the $\mathrm{Q}_{\mathrm{f}}$ curves, indicating that increased fixed charge will only increase the effective lifetime up to a certain point. The electrodes used for charging the surface layers on the lifetime samples are $\sim 36$ times larger area the typical C-V electrodes and are therefore much more prone to current leakages through pinholes. Many attempts were made to obtain data on the lifetime improvements of $\operatorname{SiNx}(\mathrm{A})$, but this was regrettably not possible as this layer seems to be more prone to leakage.

Figure 4 shows the effective lifetime as a function of voltage measured by PL-V together with the simulated results. All three samples reveal the same trend: The effective lifetime decreases as a small negative voltage is applied, as the native positive fixed charge is compensated by the external bias. With further increase in negative voltage, the lifetime reaches a minimum level (depletion) before it increases

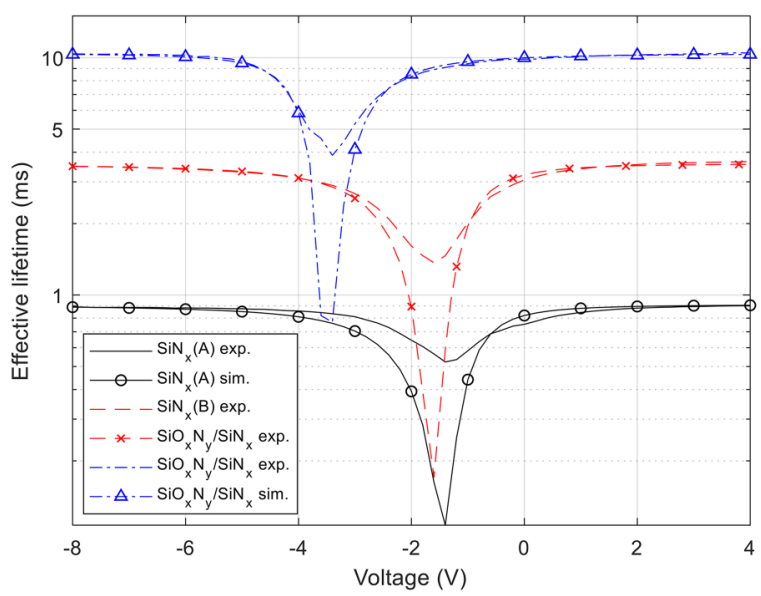

FIG. 4. Effective lifetime as a function of voltage with the PL-V method for experiment and simulation. 
as the sample reaches accumulation. With increasing positive voltage, the lifetime increases as the surface is pushed further into inversion. The PL-V curves are slightly asymmetrical about the minimum level, with the higher lifetime in the inversion state for the nitrides and in the accumulation state for the oxynitride stack. At zero bias, $\mathrm{SiN}_{\mathrm{x}} \mathrm{O}_{\mathrm{y}} / \mathrm{SiN}_{\mathrm{x}}$ was already close to maximum lifetime, indicating that charging the film has little effect on improving SRV. For $\operatorname{SiN}_{\mathrm{x}}(\mathrm{A})$ and $\mathrm{SiN}_{\mathrm{x}}(\mathrm{B})$, the effect was somewhat more pronounced, indicating that increasing the fixed charge in these samples does have an effect on improving the effective SRV. This is consistent with the soaking experiments and also with the findings in the work by Bazilchuk et al. ${ }^{4}$ It should be noted that the PL-V curve for $\operatorname{SiN}_{\mathrm{x}}(\mathrm{A})$ was recorded using a higher flux than for the other two samples, and therefore appear lower in effective lifetime relative to the other curves.

As described above, there is currently a large research effort conducted to demonstrate PQEDs as a new primary standard for detection of light. This could in turn be used to determine the ratio of the natural constants $e / h$ with improved accuracy (error of $<1 \mathrm{ppm}$ ). Current PQED detectors have been demonstrated with an internal quantum deficiency (IQD) of $<100 \mathrm{ppm}$. To achieve a sufficiently high degree of detection accuracy, an improved PQED detector must achieve an IQD below $\sim 10 \mathrm{ppm}$ or preferably below $\sim 1 \mathrm{ppm}$. Device simulations on photodetector performance were performed based on the fitted parameters in Table II for $\mathrm{SiN}_{\mathrm{x}}(\mathrm{B})$ and $\mathrm{SiN}_{\mathrm{x}} \mathrm{O}_{\mathrm{y}} / \mathrm{SiN}_{\mathrm{x}}$. The effect of soaking voltage was achieved by varying the fixed charge density. Figure 5 shows the resulting simulated internal quantum deficiency (IQD) as a function of wavelength. The illumination is implemented with an absorbed optical power around $100 \mu \mathrm{W}$ and an area of $3 \times 3 \mathrm{~mm}^{2}$ in a real device. The model clearly predicts a lowering of IQD with increasing charge density and internal losses well below $1 \mathrm{ppm}$ for certain wavelengths for both the nitride monolayer and the oxynitride stack. We therefore conclude that currently both the $\mathrm{SiN}_{\mathrm{x}} \mathrm{O}_{\mathrm{y}} / \mathrm{SiN}_{\mathrm{x}}$ stack and the $\mathrm{SiNx}$ monolayer after the application of charge increasing techniques could be suitable for highly accurate PQED detectors.

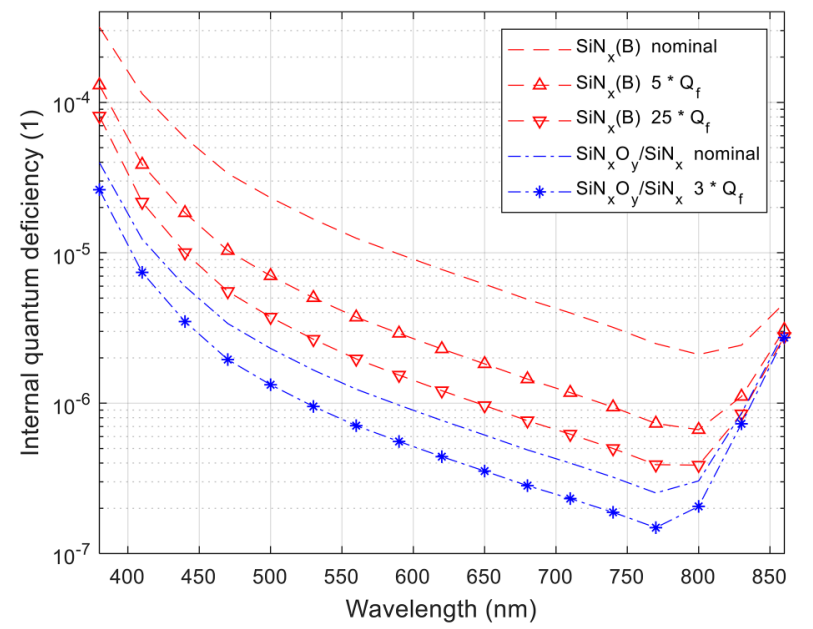

FIG. 5. Simulated internal quantum deficiency as a function of wavelength based on fitting parameters for $\operatorname{SiN}_{x}(B)$ and $\operatorname{SiN}_{x} O_{y} / \operatorname{SiN}_{x}$. The simulations show that IQD decreases as the fixed charge density increases.
Further improvements in passivation quality and increased fixed charge density will, however, be beneficial to improve the detector performance over a wider range of wavelengths.

\section{SUMMARY}

We have investigated three different passivating films for use in potential PQEDs: two monolayer films of $\mathrm{SiN}_{\mathrm{x}}$ with different compositions and one double-layer stack of $\mathrm{SiN}_{\mathrm{x}} \mathrm{O}_{\mathrm{y}}$ capped with $\mathrm{SiN}_{\mathrm{x}}$. All films exhibit very good passivation properties after deposition and annealing, with the oxynitride stack providing the best passivation, resulting in an effective lifetime close to $20 \mathrm{~ms}$. Minority carrier lifetime measurements as a function of injection level and varying surface potential can be well described by a TCAD simulation model, providing a detailed description of the surface band bending and recombination properties, which is in good agreement with $\mathrm{C}-\mathrm{V}$ measurements. Based on the passivation properties alone, photodetector device simulations predict that a photodiode made with this passivation layer would have an IQD well below $1 \mathrm{ppm}$ for certain wavelengths at room temperature. However, the oxynitride stack may be limited by absorption, as indicated by the value of the extinction coefficient, and this needs to be investigated further. The nitrides have much lower estimated absorption coefficients, and device simulations show that the most promising nitride also has the possibility to generate photodiodes with an IQD below $1 \mathrm{ppm}$ after increasing the fixed charge in the layer.

The excellent passivating properties and low estimated IQDs make the oxynitride stack and the nitride monolayers good candidates as passivating layers in a new type of selfinduced photodiodes.

\section{ACKNOWLEDGMENTS}

The authors want to thank the Norwegian Research Counsel for funding through the Public Sector Ph.D. program, Project No. 242777.

${ }^{1}$ M. Sildoja, F. Manoocheri, M. Merimaa, E. Ikonen, I. Müller, L. Werner, J. Gran, T. Kübarsepp, M. Smid, and M. L. Rastello, Metrologia 50, 385 (2013).

${ }^{2}$ I. Müller, U. Johannsen, U. Linke, L. Socaciu-Siebert, M. Smid, G. Porrovecchio, M. Sildoja, F. Manoocheri, E. Ikonen, J. Gran, T. Kübarsepp, G. Brida, L. Werner, I. Mueller, U. Johannsen, U. Linke, L. Socaciu-Siebert, M. Smid, G. Porrovecchio, M. Sildoja, F. Manoocheri, E. Ikonen, J. Gran, T. Kuebarsepp, G. Brida, and L. Werner, Metrologia 50, 395 (2013).

${ }^{3}$ M. A. Juntunen, J. Heinonen, V. Vähänissi, P. Repo, D. Valluru, and H. Savin, Nat. Photonics 10, 1 (2016).

${ }^{4}$ A. G. Aberle, Sol. Energy Mater. Sol. Cells 65, 239 (2001).

${ }^{5}$ M. Bazilchuk, H. Haug, and E. S. Marstein, Appl. Phys. Lett. 106, 143505 (2015).

${ }^{6}$ J. Seiffe, L. Gautero, M. Hofmann, J. Rentsch, R. Preu, S. Weber, and R. A. Eichel, J. Appl. Phys. 109, 34105 (2011).

${ }^{7}$ X. Cheng, H. Haug, M. D. Sabatino, J. Zhu, and E. S. Marstein, IEEE J. Photovoltaics 6, 1103 (2016).

${ }^{8}$ C. Zhou, J. Zhu, S. Zhou, Y. Tang, S. E. Foss, H. Haug, Ø Nordseth, E. S. Marstein, and W. Wang, Prog. Photovoltaics Res. Appl. 25, 23 (2017).

${ }^{9}$ S. Park, H. Park, D. Kim, J. Nam, J. Yang, D. Lee, B. K. Min, K. N. Kim, S. J. Park, S. Kim, D. Suh, D. Kim, H.-S. Lee, and Y. Kang, Curr. Appl. Phys. 17, 517 (2017).

${ }^{10}$ H. Haug, Ø Nordseth, E. V. Monakhov, and E. S. Marstein, Sol. Energy Mater. Sol. Cells 106, 60 (2012). 
${ }^{11}$ H. Haug, S. Helland, O. Nordseth, E. V Monakhov, and E. S. Marstein, in 26th European Photovoltaic Solar Energy Conference and Exhibition, Hamburg, Germany (2011), p. 1524.

${ }^{12}$ H. Haug, S. Olibet, O. Nordseth, and E. Stensrud Marstein, J. Appl. Phys. 114, 174502 (2013)

${ }^{13}$ R. A. Sinton, A. Cuevas, and M. Stuckings, in 25th IEEE Photovoltaic Specialists Conference, Washington, DC, 13-17 May 1996 (IEEE, 1996), p. 457.

${ }^{14}$ E. H. Nicollian and J. R. Brews, MOS (Metal Oxide Semiconductor) Physics and Technology (Wiley, 2003).
${ }^{15}$ T. Trupke, B. Mitchell, J. W. Weber, W. McMillan, R. A. Bardos, and R. Kroeze, Energy Procedia 15, 135 (2012).

${ }^{16}$ Cogenda Genius TCAD manual, version 1.9.0 (2016), see http:// www.cogenda.com/article/downloads/public/documentation/genius_ug_en. pdf.

${ }^{17}$ A. G. Aberle, S. Glunz, and W. Warta, J. Appl. Phys. 71, 4422 (1992).

${ }^{18}$ A. Richter, F. Werner, A. Cuevas, J. Schmidt, and S. W. Glunz, Energy Procedia 27, 88 (2012).

${ }^{19}$ T. Tachibana, D. Takai, T. Kojima, T. Kamioka, A. Ogura, and Y. Ohshita, ECS J. Solid State Sci. Technol. 5, Q253 (2016). 